\title{
The Complications of Learning and Understanding English Prepositions among Students at AL Imam AL Mahdi University in Sudan
}

\author{
Amin Ali Al Mubarak \\ Department of English language, AL Imam AL Mahdi University, Sudan
}

\begin{abstract}
The purpose of this study is to show the difficulties and analyze the various problems Sudanese students in the Arts College in the University of AL Imam AL Mahdi, face while learning and comprehending English prepositions. The focus of this study is therefore, on categorizing the types of challenges faced by these students. The research methods used were a survey followed by a report based on the results of the survey. The survey which comprised 12 items, explored the types of challenges faced by the respondents while learning the English prepositions. To portray the types of challenges faced by the students, the survey responses were analyzed and reported. In the report, the researcher described the problems and also suggested recommendations on the ways to overcome the challenges faced by the students. Thus, the findings of the study portrayed the factors which contributed to the problems in learning prepositions and also the ways to overcome these challenges. It is hoped that the findings of this survey and the suggested recommendations, will assist teachers in their classroom teaching of prepositions in the University of AL Imam AL Mahdi.
\end{abstract}

Index Terms - prepositions, students, problems, and challenges

\section{INTRODUCTION}

English language is a global language which most people of the world wish to master, not excepting Sudanese leaners. Thus, in Sudan, teaching and learning English has taken a prominent place in the world of education. Albeit such enhancement in the education arena, Sudanese learners are finding it difficult to use prepositions, one of the eight components of Parts of Speech, appropriately. Their problems lie with their inability to select the right preposition according to context and determine the place of the preposition. The main reason for this challenge is the unpredictable collocation that prepositions have with the context used. For example, the preposition "on" is often confused when it is collocated with "field", is it "in the field" or "on the field" or "at the field"? In this context, it is clear why English language learners face difficulties in not only choosing the appropriate preposition but also explaining the context of the chosen preposition. Furthermore, (Taiwo, 2004) in his study demonstrated that English as Second language learners blunder in their collocation despite adequate linguistic and lexical knowledge. In order to overcome this problem, suitable strategies need to be found and used to teach language structure, in particular preposition. However, mastering the use of preposition is not an easy feat. According to (Lam, 2009), teachers used the traditional method of teaching preposition individually within context, with no further expansion. This means, prepositions are learnt context by context with no means for predictability. Such strategy of trying to remember a list of individual, unrelated uses is not conducive for learners to understand the how the prepositions are used and why they are able to express a wide range of meanings. Therefore, in this study, the researcher would reveal the challenges the Sudanese learners face while learning English prepositions and also suggest recommendations on how to overcome these issues.

\section{THE PROBLEM STATEMENT}

English prepositions, are in general, monosyllabic, for example: on, in, from, to, for, and or. Apart from that, the use of prepositions in context varies greatly from one language to another. Recognizing such variety may be a major problem among non-native or incompetent language users. This incompetency may further result in wrong interpretation both syntactically and morphologically. This clearly indicates that learners cannot depend on their prepositional knowledge from their mother tongue. If students do make conventions of semantic correspondence between the first and second languages, it often results in prepositional mistakes (Lam, 2009). Finally, the vast number of prepositions in the English language also contributes to their trouble, which contributes the language learners' inability to systemize English prepositions (Catalán, 1996). In the exploration of the problems faced by English Second language learners, it is found that the usage and the functions of English prepositions have been one of the prominent suffering spots for most students regardless of their competency in the English language (Collins, 1991).The focus of this paper is to find out the difficulties faced by the students while learning English prepositions. More importantly, this 
study opens the doors to the understanding of the extant of difficulty that the Sudanese English Language learners face while learning English preposition.

\section{RESEARCH QUESTIONS}

1. What are the challenges faced by English as Second language students while using English prepositions?

2. What types of problems do the English as Second language student's face while using English prepositions?

\section{OBJECTIVE OF RESEARCH}

1. To demonstrate the problems faced by students while using English prepositions.

2. To overcome the issues faced by students while using English prepositions.

\section{SignifiCANCE OF THE STUDY}

The study explored the challenges faced by a group of AL Imam AL Mahdi University (Sudan)'s ESL learners in the use of English prepositions. Therefore, the researcher intended through this study to assist both educators and English as Second language learners to know more about the difficulties in employing vocabulary learning strategies.

\section{REVIEW OF THE LITERATURE}

The content of this chapter covers the central concept and significance of using prepositions in English language and reviews the previous studies related to the difficulties that students face in learning English prepositions.

Learning a second language is considered to be a complicated process with its related challenges. As claimed by (Krashen and Biber, 1988) there are two independent systems of second language performance: First, the acquired scheme which is the product of a subconscious procedure similar to the method when children learn their mother tongue. It entails meaningful conversation in the target language where natural communication takes place; here, speakers are concentrating not in their form of utterances but rather in their communication ability. Second, the learned system is the creation of formal instruction and it includes a conscious procedure which leads to the knowledge of the language such as grammar rules. Learning English preposition is closely related with the acquisition and learning process as well as the meaning and communicative aspect. This means English for Second language learners have to know the grammatical rules that govern the preposition usage. Several scholars have pointed out that the cause of difficulties in learning a foreign language is mother tongue interference. For instance (Habash, 1982) claimed that one of the hardest areas of learning is foreign language acquisition. Thus, her primary objective of her study was to explore the causes of errors in the use of English prepositions that are regularly made by Arabic -speaking students. In her study, Habash found that the cause of the difficulty in acquiring a foreign language is mother tongue interference. This challenge resulted from students putting great effort in finding and learning English language structures which were similar to their first language rather than learning the structures which are entirely different and unique to the target language. As mentioned earlier by (Lam, 2009) prepositions can be problematic to identify, mainly in spoken, because a significant number of English prepositions are monosyllabic or with very few syllables. Consequently the language learners might not be proficient enough to distinguish prepositions in quick, naturally taking place speech. Furthermore, the use of prepositions in context differs from one language to another, often creating the negative syntactic transfer.

(James, 2007) reflected Lam's claimed that English prepositions are difficult to master because, different language possesses different set of rules for the usage of preposition. These differences are bound to conflict with the rules of English prepositions which consequently, make learning of English prepositions challenging. Seeing this, (Evans and Tyler, 2005), proposed a new strategy called Cognitive Linguistics to understand and use prepositions effectively. This strategy allows learners to form a locative relationship by subconsciously thinking about each preposition with a dominant meaning in the form of mental images.

\section{Previous studies}

According to Collins (1991), the most recurrent words of the English Language are prepositions in and there is a minimum of one preposition in most of the English language sentences. (N'da Koffi, 2010) said that to be able to decide what instructional methods are most effective, it is significant to first understand the problems faced by learners while learning prepositions. The challenge of learning prepositions can be due to several factors. First, prepositions are polysemous. Polysemy is a semantic representative that means the coexistence of many possible meanings for a word or phrase. Secondly, virtually all of prepositions in English have a diversity of meanings depending on context. Therefore, learners often become confused when trying to decide prepositional meanings and when wanting to use them in a suitable manner. Meanwhile, (Zughoul, 1979) highlighted that the Saudi Arab- learners of English as Second Language faced unique difficulties in learning English language prepositions because of the following reasons: First, the Traditional methods of teaching like grammar translation Instruction method which encourages students to translate in their minds. Second, the interference of mother tongue with the second language when using prepositions. Moreover, (Scott and Tucker, 1974) pointed out that English prepositions hardly resemble Arabic prepositions. Their study discovered that around two-thirds of the mistakes in prepositions appeared due to native- language Arabic interference 
while the unnecessary use of prepositions had its source chiefly in Arabic language. The substitution of prepositions originates from both Arabic and English forms. They concluded that Arab English as Second language learners learn the semantic sense of the English lexical prepositions before they learn all the constraints on their usage. Furthermore, (Hashim, 1996) stated that most of the researchers concentrated on the syntactic mistakes, which Arab English as Second language students made when they used prepositions. In short, the syntactic errors made by the learners are mainly due to the effect of mother tongue on their second language learning. (Nayef and Hajjaj, 1997) reported that during a study on Saudi Arab English as Second Language learners' mistakes, they found that the majority of these learners' errors their faults are in English syntax which led to their conclusion that Arab students' persistent problem is in learning English prepositions which is the most challenging aspect of syntax.

(Hamdallah and Tushyeh, 1993) carried out a contrastive analysis of selected English and Arabic prepositions with instructive implications. They discovered that prepositions pose a learning difficulty to the English as Second Language learners because there are lesser prepositions in the Arabic language and their usage differs from that of English prepositions. (Al-Marrani, 2009) carried out a comparative research of prepositions in Arabic and English. The findings revealed that there are resemblances and variations between Arabic and English prepositions. The resemblances between them simplify the process of learning the English prepositions, however, the differences make learning English prepositions difficult which result in English language learners making many mistakes in their usage of the prepositions. (Gass and Selinker, 1983) reported that English prepositions have always been a source of great trouble for English Language learners irrespective of his or her mother tongue. English Language learners frequently attempt to relate the usage of English prepositions to their first language prepositional system. In various cases, the difference in the number of prepositions and the absence of a one to one mapping between the English and the first language prepositions is the basis of the difficulty. Moreover, since prepositions usage in English can be extremely idiomatic (particularly in phrasal verbs and preposition verbs), even the smallest difference in the idiomatic usage of the English prepositions poses extreme difficulty to English language learners because even the native speakers are unable to ascertain the correct form of the prepositions. (Blom, 2006) highlighted that English language learners have problems in the usage of English prepositions. She revealed that the learners performed better in the usage of prepositions if they were to use their own prepositions or if they were given multiple choice answers to select from. The nine prepositions which are repeatedly misused are "to", “in", “at", "of”, “for", 'about","on", "by" and "with". (Blom, 2006) study portrayed learners' tendency to translate from their mother tongue when they face problems choosing the appropriate prepositions in English. This tendency to resort to mother tongue results in either positive or negative interpretation depending on the resemblances of the languages.

(Hendricks, 2010) explained the difficulty in learning preposition by clarifying how the same prepositions can be used for two different situations. For example: the prepositions, on, at and in are used to express time, while the same prepositions are also used to represent the place. Therefore, learners choose a preposition by guessing and being uncertain with their choice. Furthermore, she reported that there were rules which were unhelpful old rules which are still minded such as the rule "about not ending the sentence with a preposition. The difficulty in choosing the appropriate English prepositions is further extended to differences within British and American English. For instance, in American English, they say "filling out a form" while British English it is common to say "filling in a form." As a result, Hendricks proposed that English language learners should rely on extensive reading, memorization, in order to learn how to use prepositions. (Bond, 2007) reported that mastering the uses of preposition is challenging for English as Second language learner because English prepositions have varied functions. As such, learners find it difficult to remember and understand the different uses and meanings of the preposition. Bond also showed in his study that inductive learning through memorizing prepositions and their uses has been the mode of instruction over time. Therefore, his findings show that learners lack the basic understanding of the various prepositions and how they work. In order for learners to become successful English language speakers, Bond recommended that they be immersed in a totally English speaking environment or their education be a blend of inductive and deductive teaching and learning strategies.

To summarize, the different studies on the difficulty of learning prepositions discussed, attest that preposition is a widely researched subject globally. However, Sudanese English as second language learners, in particular AL imam AL Mahdi University English language learners' challenges in learning prepositions has not been explored and studied thus far. Hence, the researcher hopes to spark the interest for further research in the learning of prepositions in Sudan through this study.

\section{SAMPLE OF THE STUDY}

The respondents sampled in this study were selected from a group of second year students at the AL Imam AL Mahdi University in Sudan. The criteria for choosing the respondents were: students must have achieved $80 \%$ or more pass grade in their last exam; second year undergraduates learning English language four skills and be native speakers of Arabic language. Forty five students aged between 20 years and 22 years old were chosen.

\section{DATa COLlections}


One instrument i.e., a questionnaire, for identifying the complications which arise when using English prepositions among AL Imam AL Mahdi University students.

\section{DATA ANALYSIS}

A quantitative method was used in collecting the data: a questionnaire was administered in order to identify The Complications of using English Prepositions among AL Imam AL Mahdi University students. The number of respondents involved in this study was 40 , and their identity was kept confidential.

\section{RESPONSES TO THE QUESTIONNAIRE}

A questionnaire was administered to find out the possible complications which arise when AL Imam AL Mahdi University students use English prepositions. The respondents answered the questions listed below:

\section{A. The Lack of Basic Knowledge of Prepositions and Their Multiple Usage Is One of the Prominent Difficulties That} You Face

Figure 10.1 demonstrates the frequency tally of responses to the statement: The lack of basic knowledge of prepositions and their multiple usages is one of the prominent difficulties that you face. Out of the 40 participants, eighty-three percent strongly agreed that the lack of basic knowledge of prepositions and their multiple usages is one of the prominent difficulties that they face. Meanwhile, ten percent of the participants agreed with this statement. However, seven percent of the participants disagreed with this while one percent strongly disagreed with this statement.

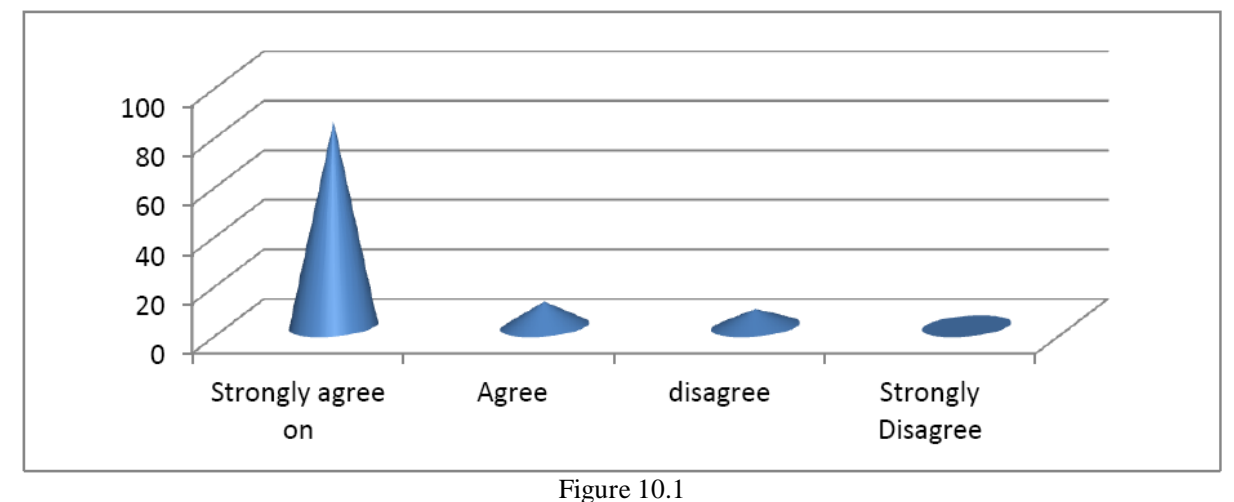

\section{B. The Lack of Communication with English Language Native Speakers Is One of the Problems Faced by You in Understanding Prepositions}

Figure 10.2 demonstrates the frequency tally of responses to the statement: The lack of communication with English language native speakers is one of the problems faced by you in understanding prepositions. Among the 40 participants, sixty-eight strongly agreed that lack of communication with English language native speakers is one of the causes of poor understanding of prepositions. Twenty-four percent of the participants agreed while a mere seven percent and one percent disagreed and strongly disagreed respectively to statement.

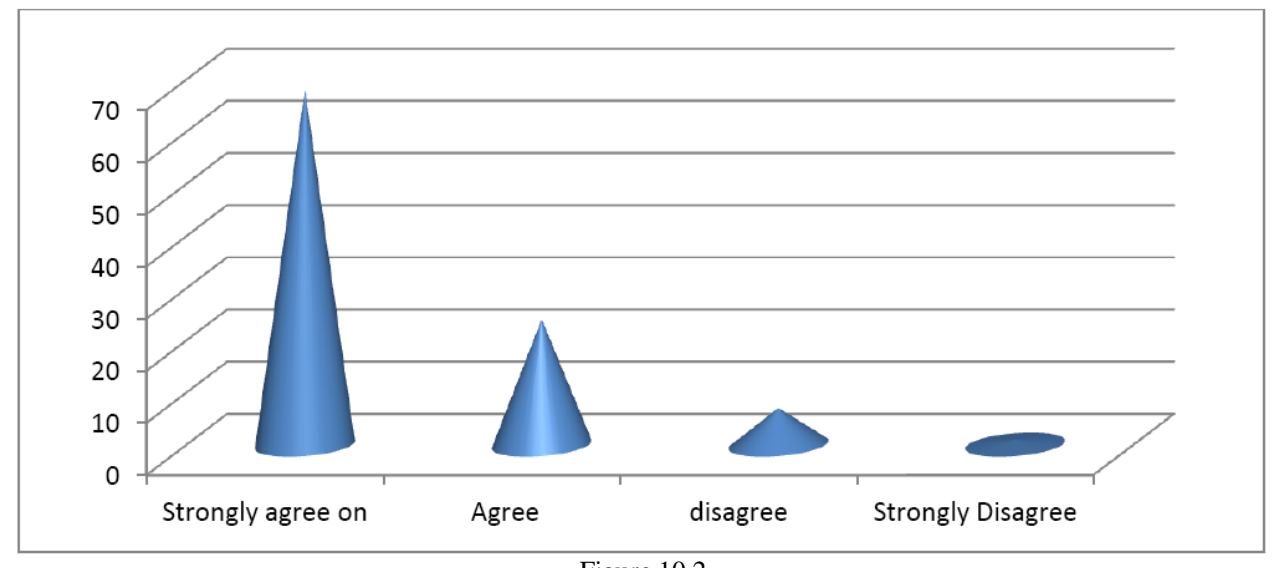

Figure 10.2

C. There Is an Urgent Need for a Well-designed Grammar Course Book That Explains to You the Syntactic and Semantic Usage of Prepositions in Different Contexts 
Figure 10.3 demonstrates the frequency tally of responses to the statement: There is an urgent need for a welldesigned grammar course book that explains to you the syntactic and semantic usage of prepositions in different contexts. From the 40 participants, ninety-one percent strongly agreed that there is an urgent need for a well-designed grammar course book on syntactic and semantic usage of prepositions in different contexts. Meanwhile, six percent of the participants agreed with this statement. However, two percent and one percent of the participants disagreed and strongly disagreed with this statement

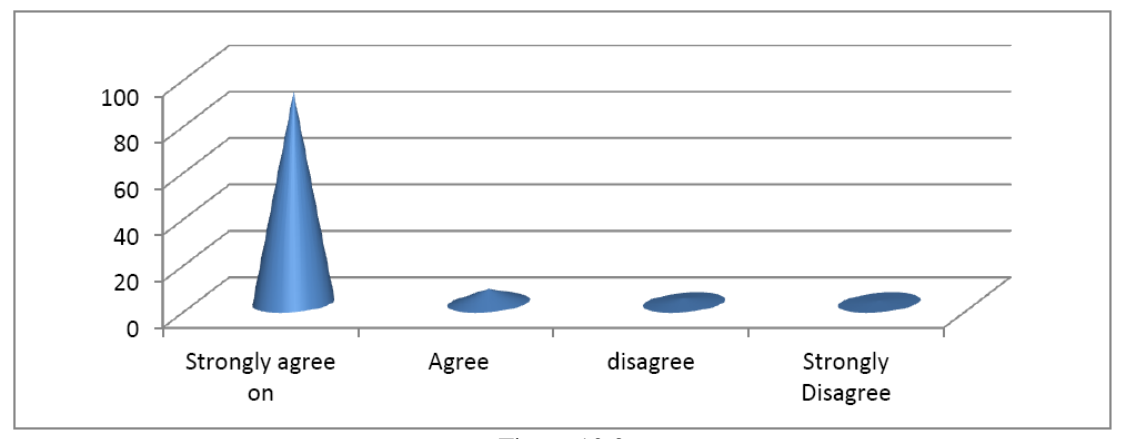

Figure 10.3

\section{The Challenge to Master the Correct Usage of Prepositions in Different Contexts Is One of the Problems in Learning Prepositions for You}

Figure 10.4 demonstrates the frequency tally of responses to the statement: The challenge to master the correct usage of prepositions in different contexts is one of the biggest problems in learning prepositions. Out of the 40 participants, twenty-three percent strongly agreed that mastering the correct usage of prepositions in different contexts is one the problems in learning prepositions. Concurrently, twenty-four percent of the participants agreed with this statement. Nonetheless, forty-three percent of the participants disagreed with this statement while ten percent strongly disagreed.

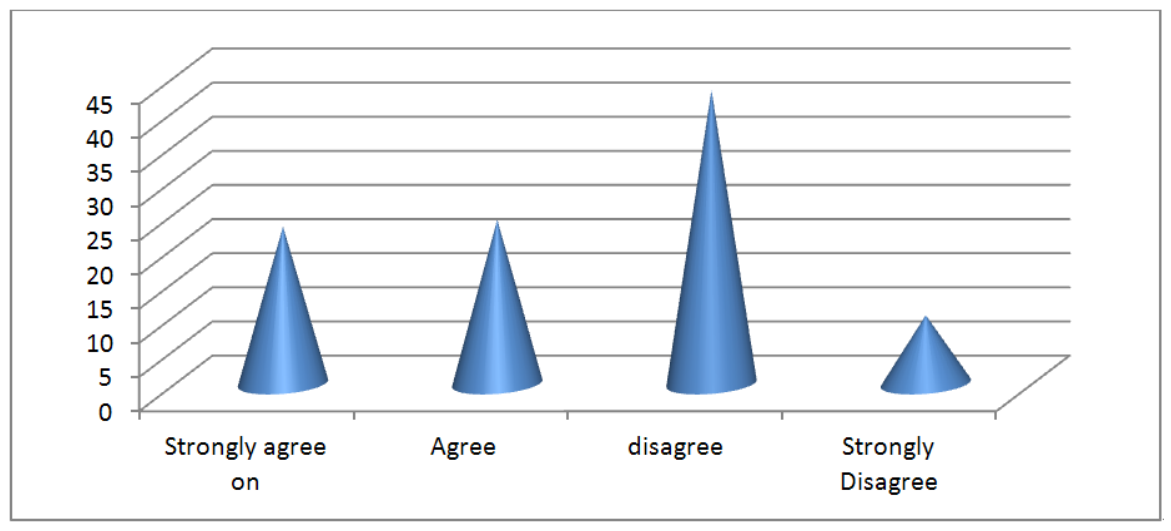

Figure 10.4

\section{E. Guessing the Use of Preposition in a Sentence is One of the Challenging Factors in Learning Prepositions for You}

Figure 10.5 demonstrates the frequency tally of responses to the statement: Guessing the use of preposition in a sentence for you is one of the challenging factors in learning prepositions. From the 40 participants, seventy-three percent strongly agreed that guessing an appropriate preposition in a sentence is one of the challenging factors in learning prepositions. Apart from that, twenty-four percent of the participants agreed with this statement but three percent disagreed. Notably, no participant strongly disagreed with this statement. 


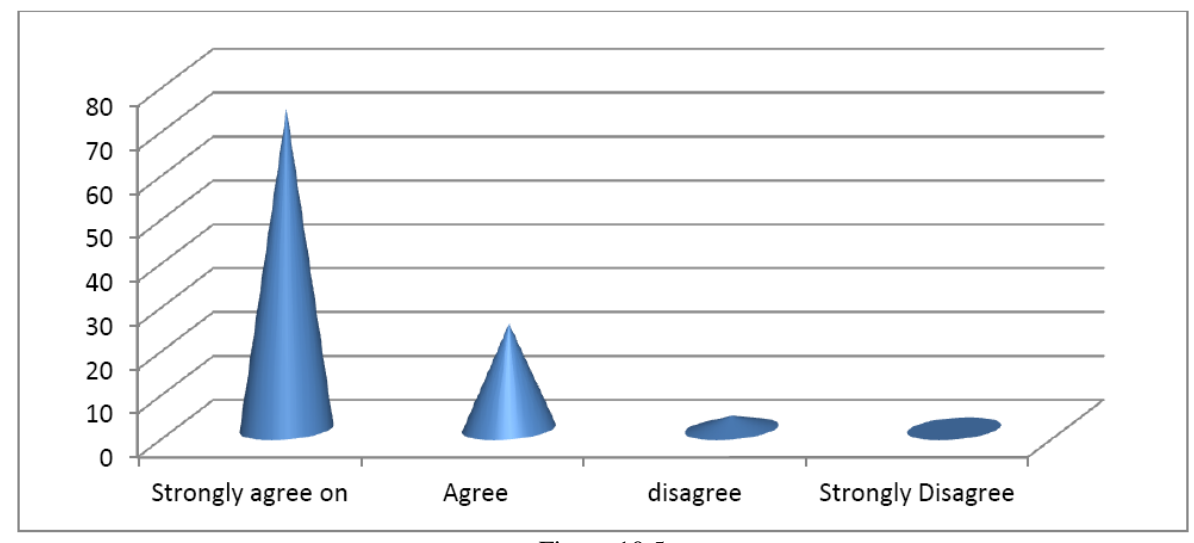

Figure 10.5

\section{F. The English Prepositions Are Highly Polysemous Words Which Are Difficult to Understand and Use for You}

Figure 10.6 demonstrates the frequency tally of responses to the statement: The English prepositions are highly polysemous words which are difficult to understand and use for you. Among the 40 participants, strongly agreed that the English prepositions are highly polysemous words which are difficult to understand and use. Not one of the participants agreed with this statement but there were nine percent who disagreed. Another nine percent of the participants strongly disagreed that the polysomic prepositions are difficult to understand and use effectively

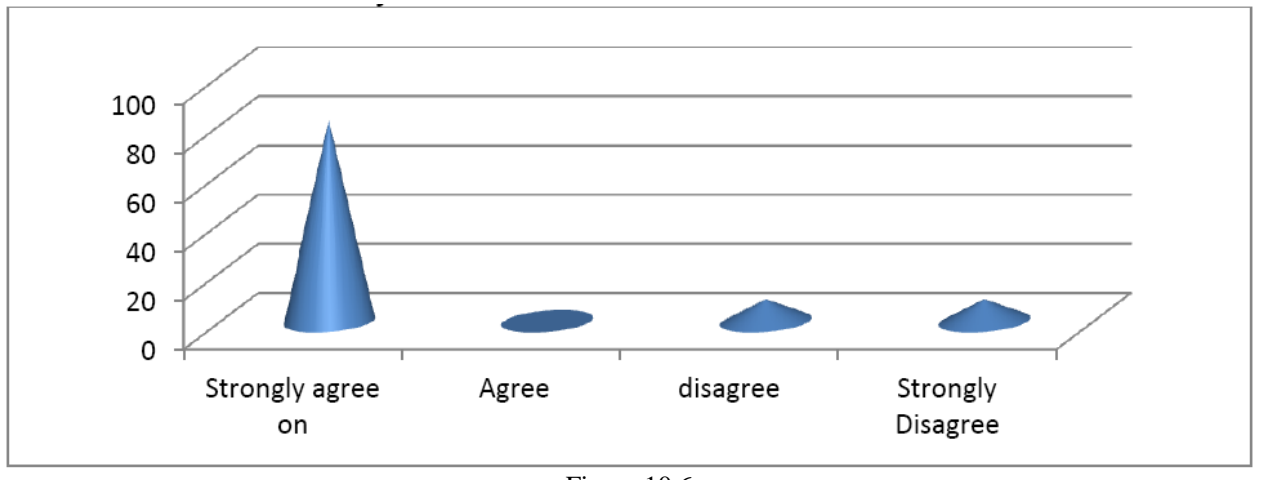

Figure 10.6

\section{G. Mother-tongue Influence Causes Problem in the Use of Prepositions in a Given Situation for You}

Figure 10.7 demonstrates the frequency tally of responses to the statement: Mother-tongue influence causes problem in the use of prepositions in a given situation for you. Sixty-two percent of the 40 participants strongly agreed that the influence of the mother tongue is a problem when learners are choosing appropriate preposition for a given situation. Furthermore, twenty- two percent of the participants agreed with this statement while, ten percent disagreed. It is worth noting that six percent of the participants strongly disagreed that mother tongue influence is a problem in using prepositions.

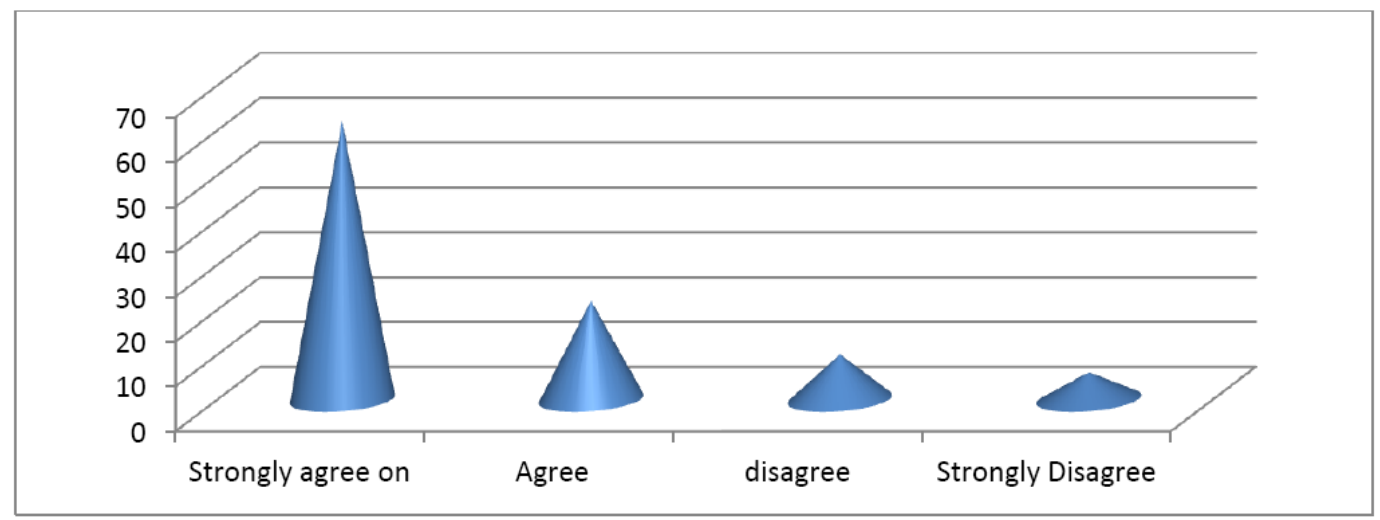

Figure 10.7

H. Does Learning Grammar Overcome the Challenges of Using English Preposition for You? 
Figure 10.8 demonstrates the frequency tally of responses to the statement: Does learning grammar overcome the challenges of using English preposition for you? Out of the 40 participants, seventeen percent strongly agreed that learning grammar does overcome the challenges of using English preposition among the English language learners. Meanwhile eight percent agreed with this statement. However, a total of sixty-five percent of the participants strongly disagreed that learning grammar can help in overcoming the challenges of using prepositions while ten percent merely disagreed.

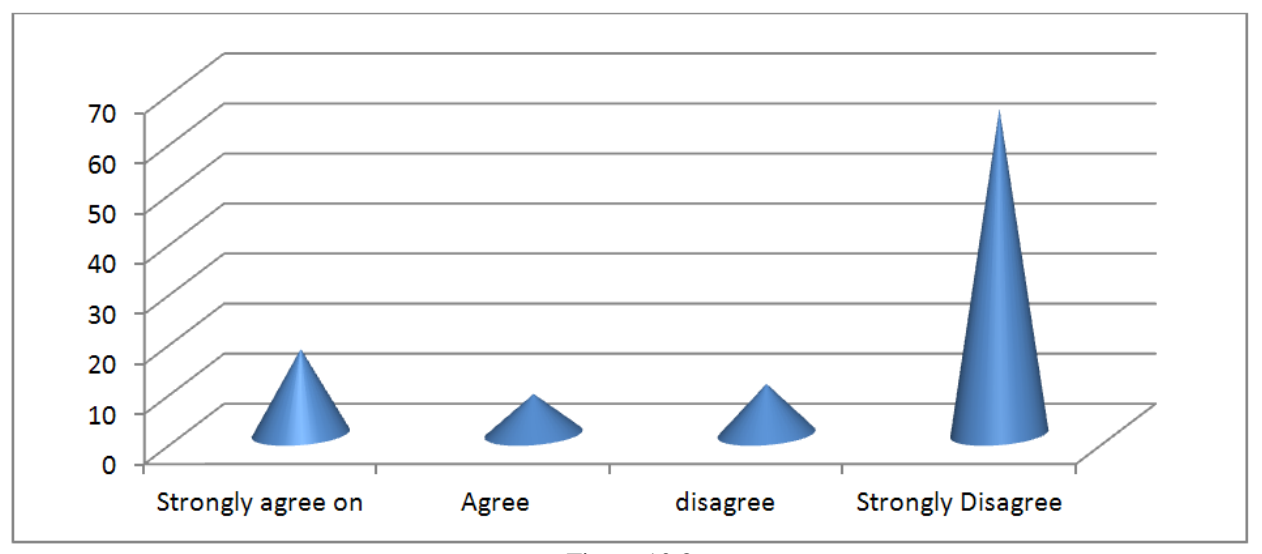

Figure 10.8

\section{The Traditional Method of Using Collocations to Teach Prepositions Create Difficulties in Understanding English Prepositions for You}

Figure 10.9 demonstrates the frequency tally of responses to the statement: The traditional method of using collocations to teach prepositions create difficulties in understanding English prepositions for you. Twelve percent of the 40 participants strongly agreed that using collocations to teach prepositions makes it difficult for English language learners to understand and use prepositions. Fifty-three percent of the participants agreed that this traditional method of teaching created difficulties in the learning of English prepositions. Nevertheless, fifteen percent of the participants disagreed that teaching collocations with prepositions causes difficulty for English language learners learning prepositions while a distinct ten per cent strongly disagreed with the statement

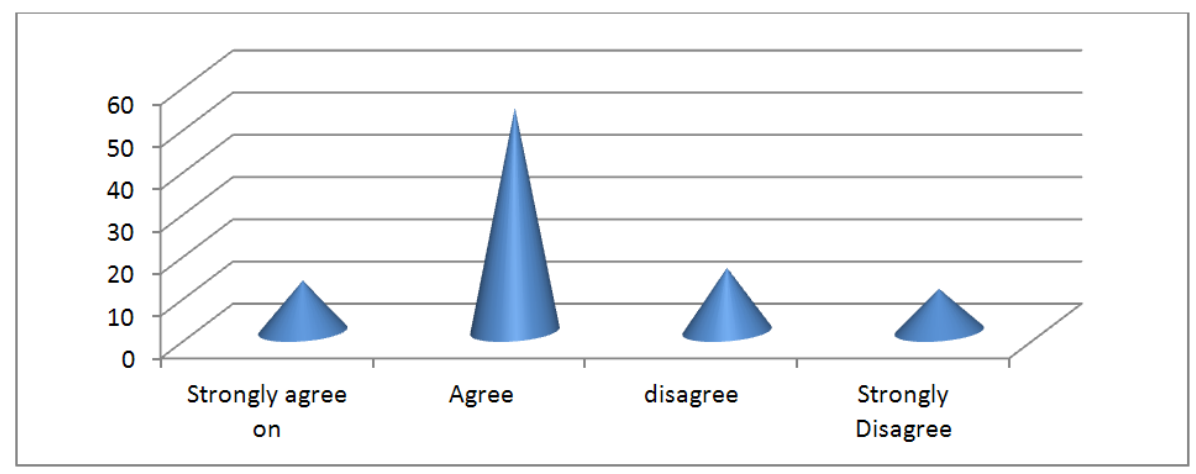

Figure 10.9

\section{J. Place and Time Prepositions Are the Most Challenging Prepositions for You in the Learning of English Prepositions}

Figure 10.10 demonstrates the frequency tally of responses to the statement: Place and Time Prepositions are the most challenging prepositions for you in the learning of English prepositions. Among the 40 participants, seventy eight percent strongly agreed that Place and Time Prepositions are the most challenging prepositions that learners faced while learning English prepositions. Furthermore twelve percent of the participants agreed with this statement. However, Ten percent of the participants disagreed while one percent strongly disagreed that the place and time prepositions are the most problematic prepositions to learn this statement. 


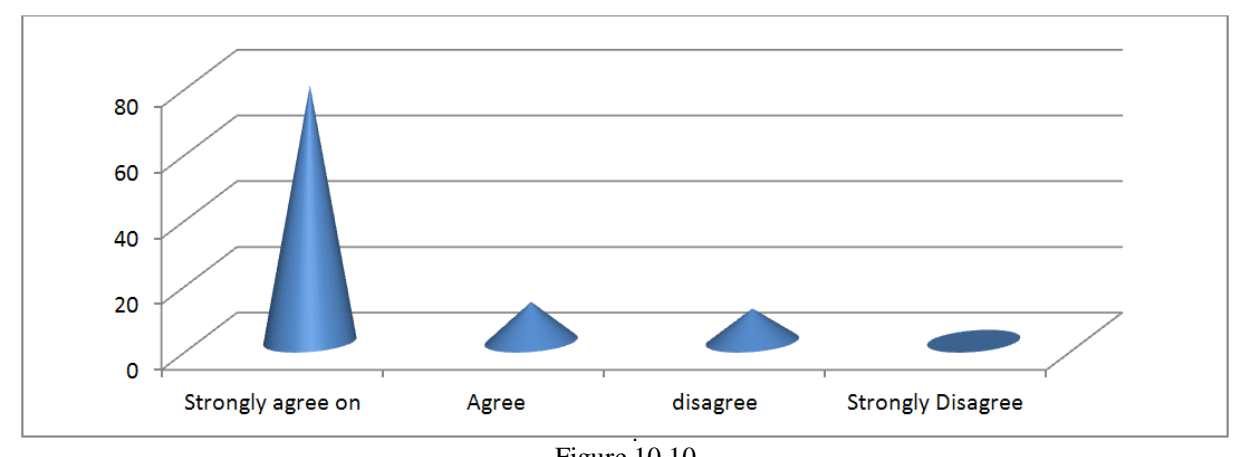

Figure 10.10

K. Prepositions Perform Three Formal Functions in Sentences. They Can Act As an Adjective, as an Adverb and a Nominal When Used in Conjunction with the Verb Form to Be, Which Create Difficulty for the Learners

Figure 10.11 demonstrates the frequency tally of responses to the statement: Prepositions perform three formal functions in sentences. They can act as an adjective, as an adverb and a nominal when used in conjunction with the verb form to be, which create difficulty for the learners. From the 40 participants, seventeen percent strongly agreed that the three functions of create difficulty for the learners. A further fifty-one percent of the participants agreed with this statement. Withal, thirty-two percent of the participants disagreed with this statement. Interestingly, 0 percent of the participants strongly disagreed with the three functions of the prepositions posing difficulty to learners.

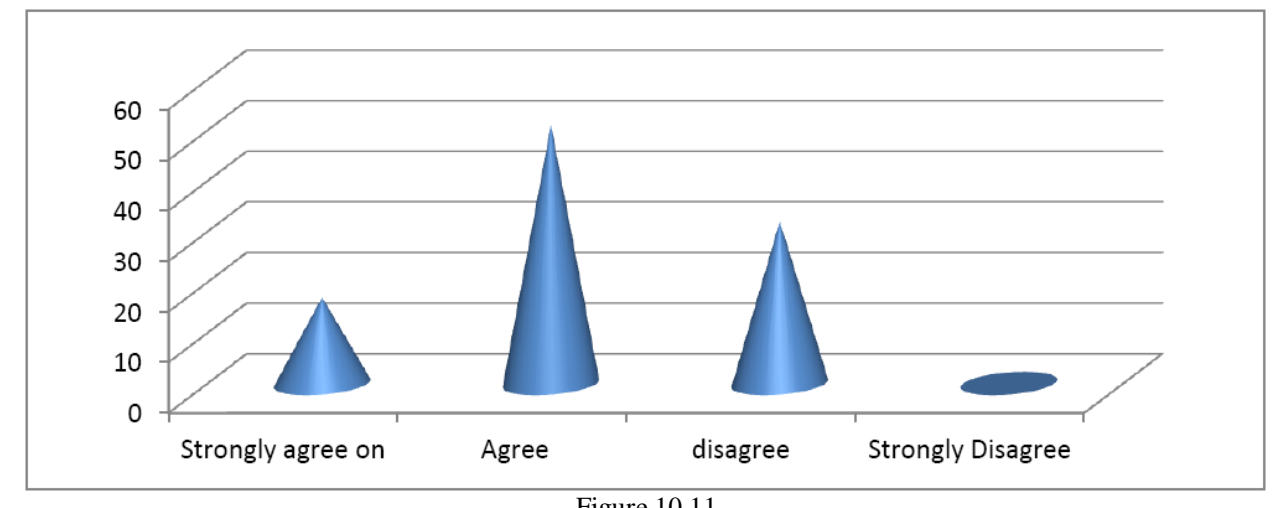

Figure 10.11

L. The Semantic Differences in the Prepositions of Arabic and English Languages Play a Crucial Role in Making It Difficult to Learn English Prepositions for You

Figure 10.12 demonstrates the frequency tally of responses to the statement: The semantic differences in the prepositions of Arabic and English languages play a crucial role in making it difficult to learn English prepositions for you. From the 40 participants, seventy-seven percent of the participants strongly agreed that the differences in the meanings of the prepositions in the Arabic and English languages play a very important role in making learning prepositions difficult for English language learners. Meanwhile, twelve percent of the participants agreed with this statement. However, seven percent disagreed and four percent strongly disagreed with the statement.

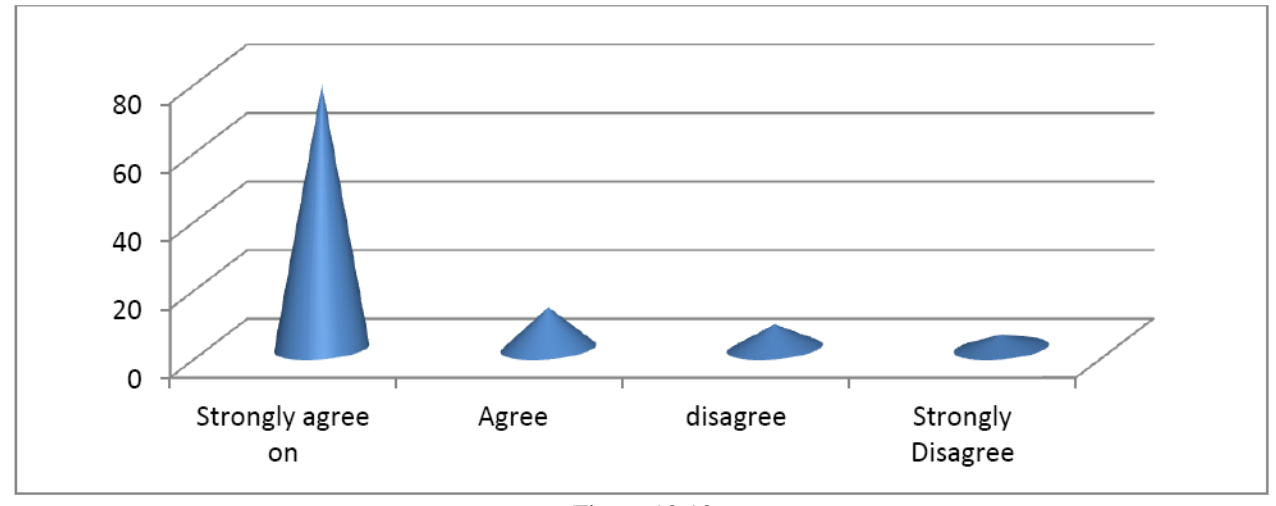

Figure 10.12 


\section{DISCUSSION}

The findings of this study confirmed (Chodorow et al., 2007)'s study which said that preposition is one of the most problematic parts of speech in English language. The complications in learning preposition arise because of the many complex roles performed by them. According (Chodorow et al., 2007), English, prepositions appear in adjuncts, they mark the arguments of predicates, and they combine with other parts of speech to express new meanings. As a result, prepositions have various syntactic roles. In addition, the complications which arise while learners learn prepositions are due to the mono-morphemic form, which means prepositions are not derived from other words. Furthermore, prepositions are non-inflecting, meaning they do not take prefixes or suffixes. As mentioned earlier, the many functions of prepositions in English language contribute to the complications which arise while learners learn to use prepositions. (Humeid, 2013) in his study stated that apart from the varied functions of prepositions in English language, there are different prepositions with the same function which result in the failure of students in using prepositions effectively. These researches findings also show that preposition with collocations also contribute to the complications which arise in the learning of prepositions. Unlike in various other grammar components, prepositions with collocations in particular do not have specific rules to be followed by the English as Second language learners. Thus, learning prepositions with collocations is a challenge for the ESL learners. This complication necessitates the educators to consciously teach the collocations to the EL learners in the classroom. Another significant finding of this result is that the Sudanese of AL Imam AL Mahdi University EL learners are not competent users of English prepositions. Moreover, they indicated in the study that they need a grammar textbook to explain the syntactic use of prepositions clearly to them. Presumably, their difficulties in the learning of prepositions are due to not having a good textbook on the learning of English prepositions. The mother-tongue or first language interference on the Sudanese of AL Imam AL Mahdi University ELL learners in the learning of prepositions was another one of the findings of this research study. The difference between Arabic and English prepositions in number, sense and usage caused challenges in learning the prepositions. Not every English preposition has a distinct correspondent in Arabic and vice versa which creates misperception for the Arabic learners to use. Also, the imperfect familiarity of how a preposition is used makes the students create some prepositional mistakes. Therefore, in order for the Arabic ELL students to learn prepositions effectively, they should be conscious of the differences and similarities between the prepositions in the two languages. In addition, semantic differences in the prepositions of both Arabic and English language prepositions also play a crucial role in causing the difficulty in learning English prepositions. is The semantic differences combined with several influences comprising the morphological, phonological, and metaphorical usage .further contribute to the complications which arise while learning to use prepositions. Such misinterpretation or misuse is the basis of the systematicity of mistakes. Moreover, these difficulties are also due to the poor presentation of prepositions in the textbook which was pointed out by (Bennett, 1975) in his study. According (Bennett, 1975) to several textbook writers emphasized only on some types of prepositions while they disregarded other concepts which they felt was not of relevance. Concepts that some textbook writers emphasis on some characteristics of the language and disregard others according to their belief or experiences. Furthermore, the findings also, revealed that the time and place prepositions are the most problematic prepositions for the University of Jazan English as Second language learners to understand and use. This is in line with (Ahmad et al., 2011) finding in his study on preposition error analysis, which asserted that errors take place because of the wrong idea of a hypothesis.

Finally, the conclusion of this research findings is that the complications which arise while learning English prepositions are caused by mother-tongue interference, mulit-functions of prepositions, inappropriate textbook on prepositions, polysemous prepositions, incompetency in the basic knowledge of prepositions and the traditional pedagogical instruction used in the teaching of prepositions as identified by (Lin, 2001). To sum up the discussion, it is important that the pedagogy used by the educators to teach the use of prepositions must be relevant to the context of the learning: is it an adverb or nominal or an adjective? If the pedagogy were suitable, then the impact of learning English prepositions will be successful.

\section{CONCLUSION}

Based on the results and findings from the study, there are significant conclusions which help to identify the difficulties faced by AL Imam AL Mahdi students English as Second language learner's face while learning English prepositions. The responses of the participants, who are studying English as a second language at the university, evidently confirm the results of the previous studies that English preposition is a great force to be contended with in an English Second Language situation. Nevertheless, as weary as it may seem, it must be learned, because the absence of good performance in English preposition will contribute to poor English language structures and misunderstanding of the language's Educators should employ teaching strategies such as Proto-type Approach, and Cognitive Strategy and Collocation Method to help English as Second Language learners overcome their problems in learning English preposition. Apart from a deliberate and focused teaching of the preposition and its associated properties in usage and meaning, a comparative analysis of the prepositions of the different languages with which English has contact with may assuage the learners' trouble. 


\section{RECOMMENDATIONS}

1. Instructors ought to indicate the differences between English and Arabic language sentence structures, in order to overcome the language obstruction and for a more successful effect in learning English prepositions.

2. A well -designed instructional method which is particularly concerned with the requirements English as Second language learners should have in order to learn English prepositions

3. Educators ought to have an inspiration disposition to energize the learning of English prepositions.

\section{REFERENCES}

[1] Ahmad, N., Ahmad, S., Bukhari, M. A., and Bukhari, T. A. (2011). The nature of difficulties in learning english by the students at secondary school level in pakistan. Journal of Education and Practice. 10(2), 18-24.

[2] Al-Marrani, Y. M. A. (2009). A Comparative and Contrastive Study of Preposition in Arabic and English. Language in India. 9(7), 55.

[3] Bennett, D. C. (1975). Spatial and temporal uses of English prepositions: An essay in stratificational semantics. London: Longman: Longman Publishing Group.

[4] Blom, L. (2006). Swedish Problems with English Prepositions. School of Learning and Communication. Jönköping University Swedish. 49.

[5] Bond, L. G. (2007). Prepositions: Their use and misuse among first year college students at Kanto Gakuin University's College of Engineering. Science (36), 39-50.

[6] Catalán, R. J. (1996). Frequency and variability in errors in the use of English prepositions. Miscelánea: A Journal of English and American Studies. (17), 171-187.

[7] Chodorow, M., Tetreault, J. R., and Han, N.-R. (2007). Detection of grammatical errors involving prepositions. Proceedings of the fourth ACL-SIGSEM workshop on prepositions, 25-30.

[8] Collins. (1991). Collins COBUILD English Guides: Prepositions Bk. 1. Collins CoBUILD.

[9] Evans, V., and Tyler, A. (2005). Applying cognitive linguistics to pedagogical grammar: The English prepositions of verticality. Revista Brasileira de linguistica aplicada. 5(2), 11-42.

[10] Gass, S. M., and Selinker, L. (1983). Language Transfer in Language Learning. Issues in Second Language Research. ERIC.

[11] Habash, Z. (1982). Common Errors in the Use of English Prepositions in the Written Work of UNRWA. MA Thesis, Birzeit University, Jerusalem.

[12] Hamdallah, R., and Tushyeh, H. (1993). A contrastive analysis of selected English and Arabic prepositions with pedagogical implications. Papers and studies in contrastive linguistics. 28(2), 181-190.

[13] Hashim, N. (1996). English syntactic errors by Arabic speaking learners reviewed. Eric. Doc. 423660.

[14] Hendricks, M. (2010). Consciousness-Raising and Prepositions. English Teaching Forum, 24-29.

[15] Humeid, A. M. A. (2013). The effect of gender and status on the apology strategies used by American native speakers of English and Iraqi EFL university students.

[16] James, M. A. (2007). Interlanguage variation and transfer of learning. IRAL-International Review of Applied Linguistics in Language Teaching. 45(2), 95-118.

[17] Krashen, S. D., and Biber, D. (1988). On course: Bilingual education's success in California. California Association for Bilingual Education.

[18] Lam, Y. (2009). Applying cognitive linguistics to teaching the Spanish prepositions por and para. Language awareness. 18(1), $2-18$.

[19] Lin, H. (2001). A grammar of Mandarin Chinese. Lincom Europa.

[20] N'da Koffi, E. (2010). Applied English syntax: Foundations for word, phrase, and sentence analysis. Kendall Hunt Publishing Company.

[21] Nayef, K., and Hajjaj, A. (1997). Errors in English among Arabic speakers: Analysis and remedy, 129-142. Beirut, Lebanon: York Press and Librainie du Liban.

[22] Scott, M. S., and Tucker, G. R. (1974). Error Analysis And English - Language Strategies Of Arab Students. Language learning. 24(1), 69-97.

[23] Taiwo, R. (2004). Helping ESL learners to minimize collocational errors. The Internet TESL Journal. 10(4), 2004.

[24] Zughoul, M. R. (1979). Teaching English Prepositions. English Teaching Forum, 24.

Amin Ali Al Mubarak is an assistant Professor of Applied linguistics at AL Imam AL Mahdi University Sudan. He earned a B.A. from Pune University India. He later earned an M.A. in linguistics from the Deccan College India. Mr. Amin Holding his PhD from Al Imam AL Mahdi University Sudan. His experience included serving as a teacher of students at the university level for 17 years. Regarding publication and books Dr. Amin publishing a number of papers in international journal with one book. 